\title{
La voz visible. \\ Un acercamiento al testimonio de ex presos políticos en Uruguay
}

The visible voice. An approach to testimonies of political prisoners in Uruguay

\section{ANA FORCINITO}

\section{UNIVERSITY OF MINESSOTA · aforcini@umn.edu}

Profesora de literatura y estudios culturales latinoamericanos en la Universidad de Minnesota. Es autora de Memorias y nomadias: géneros y cuerpos en los márgenes del posfeminismo (2004), Los umbrales del testimonio: entre las narrativas de los sobrevivientes y los marcas de la posdictadura (2012) y editora de los volúmenes Human Rights in lberian and Latin American Cultures (2009), Latin American Feminisms (2010), Human Rights and Latin American Cultural Studies (2010), entre otros. Actualmente, acaba de terminar su libro Intermitencias: memoria, justicia y poéticas de lo visible.

RECIBIDO: 15 DE JUNIO DE 2015

ACEPTADO: 15 DE SEPTIEMBRE DE 2015

DOI: 10.7203/KAM.6.6402

ISSN: 2340-1869

Resumen: La literatura testimonial de ex presos políticos uruguayos se establece como escenario para examinar las diferentes transformaciones que se producen a partir de la pretensión fundamental de ser reconocidos como víctimas de violaciones a los derechos humanos desde el propio cuerpo y desde la capacidad de pensamiento. Asimismo y a partir de un cruce de los acercamientos al cuerpo y a lo visible, este ensayo propone una poética del testimonio justamente en la transformación de la materialidad de la voz (como grito desarticulado asociado a la tortura) en una $\mathrm{voz}$ articulada que trae al campo de lo visible (en un sentido político) simultáneamente las denuncias a las violaciones de los derechos humanos y la articulación de una subjetividad ético-política que se proyecta hacia el futuro.

Palabras clave: víctimas, cuerpo, pensamiento, voz, sufrimiento.
Abstract: Testimonial literature written by Uruguayan political prisoners is established as a scenario for examining the different transformations generated by the fundamental demand of being recognized as victims of human rights violations, taking the body and the ability to think as the point of departure for the narratives. Likewise, and from different approaches to the body and the visible, this essay proposes a poetics of testimony, precisely in the transformation of the materialiality of the voice (as a broken cry associated to the torture) in an articulated voice that brings to the realm of the visible (in a political way) simultaneously the reports of human rights violations and the articulation of an ethical and political subjectivity that is projected to the future.

Key words: Victims, Body, Knowledge, Voice, Suffering. 
Ana Forcinito. Lavoz visible...

Cuando Alain Badiou se refiere, en primera instancia, a la dificultad misma de definir la justicia, propone que "la justicia es la negación de la injusticia". Y agrega: "un mundo justo sería aquel donde no habría víctimas" (2007: 20). Pero así como la definición de la justicia y su relación con los testigos y las víctimas plantea dificultades, o más bien opacidades, también sucede esto con la misma figura de la víctima, que resulta central en la producción testimonial de las posdictaduras en general y del proceso de justicia transicional uruguayo en particular. En primer lugar, porque las víctimas no siempre son reconocidas como tales: "Hay víctimas y víctimas", sostiene Badiou, algunas reconocidas pero otras no. Las primeras tienen el estatus de víctima; a las segundas, Badiou las piensa como "desechos", un concepto que de diversas formas ha habitado los testimonios y las discusiones sobre los derechos humanos de las posdictaduras. Estas víctimas que tienen derecho a reconocerse como tales, pero a quienes no se les reconoce ese derecho son denominadas por Judith Butler como "no duelables", para poner sobre la mesa que tal vez sea necesario pensar en una dimensión política en relación a la víctima (2009:22-23 ${ }^{1}$. Muchas veces damos por sentado que la agencia o el poder de gestión sirven para "desvictimizar" a las víctimas, sin considerar que en muchas instancias quienes fueron víctimas de violaciones a los derechos humanos han pasado gran parte de sus vidas luchando justamente por crear los espacios que permitan hacer visibles a las víctimas y audibles sus voces, para reclamar su estatus como víctimas y ejercer su agencia a través de esta demanda. Siguiendo a Butler y especulando sobre el duelo, podemos pensar, entonces, que ser víctima (Butler usa el concepto de vulnerabilidad) también tiene una matriz exclusionaria, que le hace preguntarse “ ¿quién es duelable o por qué algunos seres humanos son menos duelables que otros?” En definitiva, se trata de la pregunta: “¿Quién cuenta como humano?” O, tal vez ¿quién cuenta como víctima? La lógica no le sirve a Butler para contestar pero sí para proponer un ejercicio de imaginación que llevaría a proyectar la sensación de vulnerabilidad, que trae como consecuencia un duelo propio y personal, con la capacidad de pensar en el duelo de los demás, y de identificarse con la vulnerabilidad de todos y no de unos pocos. Badiou lo formula de forma diferente, porque pone en juego la noción de la justicia: "Hay vidas más preciosas que otras y ustedes ven que esto es una cuestión de justicia. La pregunta que se impone entonces es ¿Quién es la víctima? ¿Quién es considerado víctima? Estamos obligados a admitir que la idea de víctima supone una visión política de la situación"(2007:21).

\footnotetext{
${ }^{1}$ Como paso inicial, y frente al dolor, a la tortura, a la desaparición forzada de otros, Judith Butler propuso preguntarse, en primera instancia, “¿quién es duelable?”, es decir, ¿por quién, ante qué muerte sentimos dolor, a quiénes reconocemos como alguien por quien transitar un duelo? Estas preguntas como médula misma de la cuestión del duelo hacen posible sugerir que el testimonio, como trabajo que atañe a la memoria y sobre todo a un umbral donde la memoria individual se traspasa a la sociedad, intenta construir un espacio en el cual hacer justicia a las historias narradas y a quienes las vivieron para reclamar la categoría de "duelable", y con ella el trabajo, el dolor y la memoria que harán posible el reconocimiento de esa ausencia y la trama de sentidos (y sinsentidos) que la acompañan.
} 
Tomando estas consideraciones como punto de partida, este ensayo estudia, en primera instancia, la literatura testimonial de ex presos políticos en torno a los crímenes cometidos por la dictadura uruguaya, a través de la pretensión fundamental de conferir a las víctimas el espacio para que se autodenominen como tales (justamente cuando no habían sido consideradas como tales por el estado y alternaban entre las designaciones de sediciosos, rehenes y desechos). En este reclamo del que se ha sido víctima del terrorismo de estado, que tiene lugar en la construcción del testimonio, donde el testigo se reconoce como víctima, se hacen visibles las narraciones sobre torturas y tratos degradantes y por lo tanto se pone el cuerpo en el espacio de lo visible, a partir de una narración que, al mismo tiempo, se distancia de ese cuerpo evocado como cuerpo de la víctima para afirmarse como cuerpo-testigo (es decir un cuerpo pensante). Esta transformación implica una poética, aun en las vertientes del testimonio más asociadas a la denuncia, puesto que simultáneamente se expone el cuerpo de la víctima y se afirma la capacidad de pensamiento y de proyección política de ese mismo cuerpo.

En segundo lugar, y puesto que el testimonio de las víctimas (que en general implica ultrajes al cuerpo) puede generar un espectáculo de la corporalidad, este ensayo explora al testimonio como espacio de afirmación de lo que Alain Badiou piensa como el cuerpo -idea (opuesto al cuerpo espectáculo). Esto resulta central porque al hacer visible a un cuerpo sufriente (aquí Badiou se separa de esta idea de justicia construida alrededor del cuerpo sufriente, como si además de la piedad que viene del espectáculo del cuerpo sufriente que proporciona el testimonio, se produjera una noción paralela de cuerpo espectáculo que no puede formar parte del circuito de la justicia), es importante repensar el rol que el testimonio uruguayo tuvo para sostener otra idea sobre la corporalidad, una idea superpuesta a la del cuerpo que ha sufrido ultrajes y que Badiou asocia con la idea del "cuerpo creador", en el sentido de que es un cuerpo de pensamiento $(2007: 24)^{2}$.

Lo que propongo delinear entonces en el reclamo de ser víctimas, de haber sufrido en el cuerpo, y por otra parte la afirmación de un cuerpo pensante, constituido también desde lo político, y desde lo ético en la literatura testimonial uruguaya. Me centro en textos escritos por ex presos políticos, algunos de ellos rehenes (uso el masculino de ex presos para referirme a los ex presos varones, puesto que considero que la problemática del testimonio de mujeres en Uruguay debe analizarse desde un marco diferente, porque estas estuvieron excluidas de los gestos fundacionales que determinaron el pasaje a las nuevas formas de participación política de los tupamaros). Asimismo, analizo la centralidad de esta constitución de la víctima, pero también del cuerpo ligado, no solo al dolor, sino además al pensamiento, en la reflexión sobre la justicia que proponen y su relación con la amnistía y con la caducidad como instancias consensuadas de la justicia transicional.

\footnotetext{
${ }^{2}$ Lo opuesto es el cuerpo sin ideas, Badiou lo asocia al cuerpo del esclavo, cercano a la noción de vita desnuda de Giorgio Agamben).
} 
Ana Forcinito. La voz visible...

\section{Justicia, amnistía, caducidad: Disputas en las imágenes ético políticas de la transición}

Tomo como punto de partida el día de la liberación de los presos políticos, el 14 de marzo que, desde 2007 se usa para conmemorar el día del Liberado, recordando ese día de 1985 en que a las 20.04 horas los últimos presos políticos fueron puestos en libertad. Entre ellos los rehenes varones de la dictadura uruguaya, que dieron una conferencia de prensa, donde los tupamaros se comprometían a militar en el marco de la democracia. Solo días después de que Julio María Sanguinetti asume la presidencia el 1 de marzo de 1985, el parlamento aprueba la ley de Pacificación Nacional y desde el 10 de marzo hasta el 14 aproximadamente doscientos presos políticos son liberados. El artículo 1 de la ley 15737 dice: "Decrétase la amnistía de todos los delitos políticos, comunes y militares conexos con éstos, cometidos a partir del $1^{\circ}$ de enero de 1962", mientras que el artículo 5 excluye de la amnistía los delitos cometidos por funcionarios policiales o militares, equiparados o asimilados, que fueran autores, coautores o cómplices de tratamientos inhumanos, crueles o degradantes o de la detención de personas luego desaparecidas, y por quienes hubieren encubierto cualquiera de dichas conductas".

En el marco de una transición que se estructura a partir de la imagen del fin de la guerra y de la entrega de rehenes como simbolismo de un posible acuerdo de dos sectores en conflicto (la antesala de lo que será la teoría de los dos demonios uruguaya) la centralidad del testimonio resulta clave no solo en la narración de la experiencia como rehenes y presos políticos (y de denuncia en las afueras de lo judicial) sino además en la constitución de un sujeto político y ético no ya de la militancia anterior sino del proceso de justicia transicional que se gesta. El líder tupamaro Mauricio Rosencof ha de recordar varias veces los últimos treinta años su promesa a Eleuterio Fernández Huidobro de dejar testimonio de lo que vivieron, (ambos fueron rehenes de la dictadura), sobre todo, luego del suicidio de uno de los nueve rehenes, Adolfo Wasem. Aun cuando Rosencof separa el testimonio que apunta a la reconstrucción de la verdad de la denuncia con efecto en el escenario jurídico, la afirmación de lo testimonial está involucrada en la reconstrucción del sentido ético del militante político.

Una de las posibles posiciones, respecto de los procesos de justicia transicional, es que la amnistía (en relación a las violaciones a los derechos humanos) fue una "concesión inevitable" (Roht Arriaza) en la forma de un intercambio de justicia por el pasado por justicia por el porvenir. Si aquí en este marco la amnistía apunta a los presos políticos, y también reconocida como un pacto necesario para la democratización, la caducidad puede poder leerse como una concesión que ahora beneficia a los "otros demonios”. De ahí el énfasis en la pacificación, cuando la guerrilla tupamara, según algunos expertos había sido vencida ya al comienzo de la dictadura.

Para comprender el rol que juega la literatura testimonial en Uruguay es necesario mencionar algunos de los aspectos clave de su proceso de redemocratización, en especial en torno a las décadas de impunidad que siguen a la dictadura y cuyo hito ineludible es la Ley de Caducidad en 1986, a través de la 
cual se deslinda la relación entre la democratización y la justicia, separación que, de algún modo, es intrínseca al carácter pactado de la transición y del llamado Pacto del Club Naval, que fue firmado el 23 de agosto de 1984 entre representantes de los partidos políticos y las Fuerzas Armadas (Roniger y Sznadjder 199: 78-79, Caetano 2009:93). Tanto el Pacto del Club Naval como la ley de Caducidad configuran las señas más importantes de la transición uruguaya, lo que el ex presidente Julio María Sanguinetti (1985-1989) llama en su campaña El cambio en paz"para señalar a un proceso de democratización desasociado de los derechos humanos, en la cual la paz sería sostenida a través de la caducidad de la pretensión punitiva del estado "respecto de los delitos cometidos hasta el $1^{\circ}$ de marzo de 1985 por funcionarios militares y policiales, equiparados y asimilados por móviles políticos o en ocasión del cumplimiento de sus funciones y en ocasión de acciones ordenadas por los mandos que actuaron durante el período de facto" (El Referéndum Uruguayo del 16 de Abril de 1989).

De ahí que sea instrumental la construcción de una nueva subjetividad tanto en lo testimonial como en su proyección política: un sujeto que ya no es el de la militancia anterior a la dictadura sino que es capaz de producir una nueva articulación de lo político, que comienza a nacer en las más adversas condiciones: la situación de preso político y de rehén. Por eso sostengo que las narrativas testimoniales, simultáneamente con el reclamo que hacen las víctimas como tales, vienen a formar dos tipos de sujetos colectivos, el de los presos políticos (o el "puñado de viejos militantes” como dice Fernández Huidobro en 1985 en la conferencia de Conventuales) que son ahora testigos de graves violaciones a los derechos humanos, y el sujeto político colectivo que surge de la resistencia en las cárceles, de las prácticas del pueblo contra la dictadura (“fueron ustedes”, dice Fernández Huidobro en el mismo discurso en nombre de los rehenes liberados). Lo que está en juego aquí es el nuevo diálogo que se intenta producir entre el ustedes y el nosotros (el pueblo y los militantes o en muchos de los casos, de los dirigentes)

Lo que quiero marcar es que el gesto fundacional de la liberación de los rehenes, en cuanto a la imagen política de la postdictadura. La Ley de caducidad no puede entenderse fuera su propuesta de un modelo de pacificación como modelo de justicia transicional, un modelo que no excluye sino que incluye la amnistía de los presos políticos y el discurso de Conventuales. Lo que se produce aquí es una disputa político-legal. El testimonio tiene aquí una doble vinculación: dejar saber (y ahí es posible hablar de una denuncia) pero dentro del marco de un pacto político- militar, y por lo tanto con las pautas democráticas que vislumbran una transición a través de símbolos de pacificación. Ahora bien, si un estado debilitado por un pasado que en 1985 era casi presente, es legitimado por los últimos presos y rehenes que resaltan la participación del pueblo y lo convocan a participar democráticamente, la construcción de ese sujeto heroico (y no la heroicidad militar de la guerra sino la heroicidad de la resistencia y de la ética) era instrumental para generar un espacio desde el cual construirse como nuevo sujeto político (en el caso de los rehenes, de la pacificación): 
Ana Forcinito. Lavoz visible...

Ustedes tienen que comprender lo siguiente, dice Eleuterio Fernández Huidobro, nosotros todos, pero muy especialmente los que fuimos rehenes...Hemos vivido enterrado vivos[...]A nosotros nos sacó el pueblo de la cárcel, el pueblo uruguayo. Y vimos irse a todos los compañeros. Y tuvimos el orgullo de ser los últimos en irnos. Nosotros podríamos haber venido a hablar en nombre de una estrella que inventamos nosotros y de una palabra- tupamaros- que la inventamos nosotros los que están aquí presentes, y de un nombre de un movimiento que lo inventamos nosotros, y de una consigna-patria para todos- que la inventamos nosotros, pensamos que era mejor hablarles a todos ustedes, al pueblo, y le vamos a hablar y le vamos a hablar a todos los compañeros cuando nos reencontremos [...] en nombre nada más de un puñado de viejos luchadores (Las bases 20, 17 de marzo de 1985, en Ruiz y Sansaviero 2006: 13).

Marisa Ruiz y Rafael Sanseviero, que citan esta parte de la conferencia en su estudio sobre las rehenas, reflexionan sobre la transformación de estos "viejos luchadores" en actores cruciales de la política uruguaya en el presente, con José Mujica, uno de esos rehenes como presidente de la nación a partir del 2009. Además de jugar un rol central en el reagrupamiento político luego del exilio y la prisión y sobre todo en el pasaje de quienes estuvieron enterrados vivos a actores interpretativos y simbólicos, tanto la conferencia en Conventuales como los aportes testimoniales más importantes de los primeros años de la transición reconfiguran el modelo de la nueva subjetividad política de la posdictadura para reclamar por una parte y reescribir por otra la figura de la víctima en el traspaso a la subjetividad interpretativa y democrática, dentro de las pautas establecidas en estos primeros tiempos de justicia transicional. Las narrativas testimoniales juegan un rol central en el mecanismo de acusación y de construcción de archivos no oficiales que sirven en el proceso de construcción de la memoria histórica, aun cuando quedan marginadas del modelo jurídico de justicia transicional.

Este gesto fundacional de los dirigentes tupamaros sella un largo proceso de reclamo de amnistía. Los últimos años de la dictadura, sobre todo a partir de los ochenta están marcados por luchas contra la dictadura (cacerolazos, apagones), donde la amnistía de los presos políticos, fue la consigna central y alrededor de esta consigna estudiantes y partidos políticos hacen su demanda. Es un proceso de "diálogo", señalan Ruiz y Sanseviero, que dio paso a las elecciones nacionales de 1984 (y que culmina en el Pacto del Club Naval). Luego de las elecciones y con 300 presos políticos todavía presos, el debate de la amnistía vuelve a ser central a la transición (Ruiz y Sanseviero 2006:16) ${ }^{3}$. Ruiz y Sansaviero subrayan una escena fundamental de una transición que estaba desde el vamos marcada por el relato de dos demonios: la entrega de rehenes, en este marco, sellaba el fin de una "guerra" (2006:17). La amnistía representada por los medios como la liberación de los presos políticos ("los sediciosos" subrayan Ruiz y Sanseviero y agregan: "Se opera así la atribución de un significado a la amnistía a los presos y presas políticas-el perdón a los sediciosos, que será apoyo argumental a la impunidad para los

\footnotetext{
3 Ruiz y Sanseviero intentan demarcar el desplazamiento de las mujeres de esta historia y de eso de trata el texto., como por ejemplo que entre los últimos liberados hay tres mujeres rehenes que no están presentes en la conferencia de prensa.
} 
Ana Forcinito. Lavoz visible...

crímenes de la dictadura" (2006:17)). Este es uno de los momentos fundacionales de "la pacificación nacional”. En este marco, el discurso de los rehenes y la consolidación de una nueva forma política, dentro de los parámetros democráticos, por parte de este puñado de viejos luchadores también sienta las bases de una transición democrática que tendrá como segundo momento fundacional la ley de caducidad como parte muy cuestionable del proceso de justicia transicional. Ahora bien, aun cuando la ley de caducidad tampoco responde a su famoso artículo 4 sobre la responsabilidad del estado en la investigación (y recordemos que es este uno de los puntos de retorno de los debates culturales que terminarán conduciendo a la creación de la Comisión para la Paz en el 2001), tanto la conferencia de Conventuales como dos de las expresiones testimoniales más conocidas en los primeros años de la posdictadura uruguaya Las manos en el fuego y Memorias del calabozo (que discutiré a continuación) apuntan tanto a dar a conocer lo que sucedió a los presos políticos y los rehenes como a reconstruir la subjetividad política de los dirigentes tupamaros y también su autoridad (diezmada en la situación de prisión política y de rehenes) desde la reconstrucción ético- política ${ }^{4}$. Y en esa reconstucción de la subjetividad se asienta el disenso con la narrativa de la pacificación oficial que tiene como punto de referencia central la lógica de los dos demonios, del fin de la guerra, y la derrota del proyecto político de los "sediciosos", que el testimonio viene a cuestionar, no sólo desde la exposición de esas voces ahora visibles que denuncian los crímenes del estado terrorista (como cuerpo sufriente y como cuerpo pensamiento) sino además a través de la rearticulación política que traza una continuidad entre la subjetividad política del pasado y la del futuro (la subjetividad ético política y la memoria histórica).

\section{El testimonio y la víctima: lo audible y lo visible}

Muchas de las discusiones sobre la literatura testimonial en los estudios latinoamericanos se concentran, de maneras diversas, en la voz como uno de sus aspectos cruciales. Que la voz es el aspecto subrayado de la práctica testimonial puede verse incluso en algunos de los títulos del debate, entre ellos el coeditado por Hugo Achugar junto con John Beverley, La voz del otro, en el cual ponen en escena la articulación de la voz de los que quieren hablar, denunciar, o testimoniar. Se trata, por una parte, de una contraposición directa a la escritura, en muchos casos, donde se opone la "oralidad” no registrada de los márgenes dentro de la tradición literaria y por otra, del privilegio que se da a las voces que la literatura testimonial, a través de la escritura, intenta registrar. El énfasis del testimonio en la voz no deja de remitir al régimen visual, y sobre todo a la distribución de lo visible y lo invisible (y la irrupción de lo

\footnotetext{
${ }^{4}$ Ruiz señala tres momentos en la construcción de memorias masculinistas y son justamente estos tres momentos: la conferencia de los rehenes, el testimonio de David Campora en Las manos en el fuego y los testimonios de Rosencof y Fernandez Huidobro en Memorias del calabozo.
} 
Ana Forcinito. La voz visible...

invisible como visible). El testimonio no arrasa necesariamente con la preponderancia de la imagen y de la mirada sobre el otro y su invisibilidad para registrar (hacer visible) lo que aún existe, aunque sea invisible porque no es tomado en consideración, pero sí pone en escena la problemática de la voz de los que intentan hablar, con la premisa de que esas voces no son necesariamente inaudibles sino incomprensibles.

Al hablar del desacuerdo entre la política y la filosofía Jacques Rancière se refiere a esta problemática de la voz (como logos y sonido) y lo visible (e invisible) a la hora de pensar la articulación de lo político (1996:41). Esto se produce en el testimonio a través de la articulación de la voz y esto genera muchísimas discusiones en torno a la pérdida en la cual esa articulación está sustentada, sobre todo en los casos en que exista un editor. ${ }^{5}$ En el caso de que no exista un editor, la distancia entre el sonido y la voz que logra articular una experiencia que parece inenarrable ha constituido una parte considerable de la reflexión crítica y testimonial, puesto que indica el sentido de pérdida que habita al testimonio y la paradójica promesa de que hace visible y articula lo que sólo puede articularse en un umbral. ${ }^{6}$ El caso del editor lo hace más evidente, pero la ausencia del editor no implica que la voz articulada no esté señalando justamente a esos residuos no articulables de experiencias extremas, residuos que siguen conteniendo lo intraducible, y lo que se dejado de lado, pero que sigue siendo siempre lo que queda, o incluso lo que resiste, invisible, e intermitente.

En una contraposición entre silencio y voz, aislamiento y subjetividad colectiva, la narrativa testimonial sirve para reconstruir al sujeto testimonial a partir de su dimensión política, desde su historia de la militancia a la historia de la resistencia en los penales y cuarteles. Así el sujeto del testimonio como víctima de una injusticia, se resignifica narrativamente como un sujeto colectivo político e histórico. Esa recuperación requiere de dos estrategias centrales: primero, el pasaje del cuerpo sufriente al cuerpo pensamiento, acompañado por el pasaje del grito de la tortura o el silencio de la reclusión a una narrativa articulada que dé cuenta de la subsistencia de la subjetividad, y en segundo lugar, el desmontaje del salto temporal y el tiempo continuo y presente como dos características de la experiencia de reclusión sobre todo para los rehenes, que apunta a la reconstrucción histórica. Se recupera así el sentido histórico de la supervivencia.

\footnotetext{
5 Probablemente algunas de las cuestiones centrales en estas discusiones giran en torno a la autenticidad de la voz testimoniante y a la presencia (solidaria, letrada y altamente problemática) del editor y de su rol no sólo en el hacer público el testimonio sino mas bien en cómo hacerlo público, es decir, a partir de qué transformaciones de la narración misma (oral) dependía el testimonio (escrito). Para discusiones sobre el editor y el narrador testimonial véase Beverley 1989, 1992, 1993

${ }^{6}$ Remito a Los umbrales del testimonio para una discusión más completa sobre este punto.
} 
Ana Forcinito. La voz visible...

\subsection{La voz que se hace visible: Las manos en el fuego y El furgón de los locos}

En 1986 el testimonio del periodista Ernesto González Bermejo, Las manos en el fuego, basado en testimonios orales y escritos del dirigente tupamaro David Cámpora, denuncia las violaciones de los derechos humanos, y la práctica de la tortura y el asesinato de prisioneros políticos en el penal de Libertad. Asimismo, la narrativa construye la subjetividad heroica, que más allá de su clave masculina (y que además construye el sentido de lo político, de la militancia y la supervivencia en clave masculina) superpone a la afirmación del estatus de víctima del preso político en cuanto a torturas y tratos degradantes, una subjetividad que se sustenta no solo en la militancia sino además en el pensamiento. El comienzo del texto marca el punto de partida: "El silencio: lo que más le impresionó fue el silencio", comienza el narrador (1985:13). Así se marca el inicio de la detención que sigue al enfrentamiento (humo, ruidos, ambulancias, y estruendos). Luego sobreviene el silencio: "De pie en la vereda, descalzo, con las manos libres, nadie a su lado, todo aquel gentío mirándolo[...] máscaras sin expresión, sin prisa, habitantes de una campana perfecta de silencio." (1985: 13) Ese comienzo da cuenta también del desmontaje de la narrativa de la guerra que maneja el estado terrorista y que hace alusión al epígrafe del texto. La marca temporal se ubica en 1972: "Fue un infarto nacional: ese atardecer del 14 de abril de 1972, en la calle Amazonas, de Montevideo, un Uruguay había sido rematado a tiros” La imagen del infarto se explica así: "los tupamaros se desmoronaban, la izquierda legal sucumbía, los milicos inauguraban muy latinoamericanamente su dictadura" (1985:14). Varias veces vuelve a este escenario, para rectificar las versiones oficiales en 1972 a través de la representación de los medios y para reflexionar sobre la construcción de los eventos a través de las narraciones legitimadas.

La tortura es uno de los ejes de la narración: por una parte se denuncia y por otra se reconstruye la subjetividad desmontando la reducción a la corporalidad pero que aquí está reformulada desde la superposición subjetividad/corporalidad. ("La máquina, un hito crucial en la vida de un hombre, situación límite- concluiría David-y no se regresa igual de una situación límite: los valores cambian”. (1985:25)). Si bien se marca el abismo entre la subjetividad anterior y posterior a la tortura ("se despidió definitivamente de ciertas cosas, retomará otras de modo distinto, considerará algunas como absolutamente esenciales.", 1985:25)), plantea que la subjetividad, marcada por el corte y el desmoronamiento de la subjetividad anterior no destruye la memoria, sino que tiende puentes con esa identidad anterior, y es capaz de restituir un sentido histórico. La reconstrucción de lo histórico es característica de este tipo de textos que en cuanto a la temporalidad buscan ordenar cronológicamente los eventos narrados pese a la ausencia de marcas temporales que habitan la experiencia carcelaria, pero que además sugieren una eyección de ese sujeto del pasado y una proyección al futuro.

La narración testimonial que sirve como matriz evidenciaría de crímenes del estado, sirve además para restituir un sentido histórico a nivel personal y colectivo. En esta instancia se reconstruye la 
Ana Forcinito. Lavoz visible...

militancia, detención, prisión y finalmente la liberación y el encuentro con la familia. Al mismo tiempo, la narración se va interrumpiendo con la experiencia carcelaria y todo lo que de ella apunta al silencio, lo no dicho, y el corte abrupto con la posibilidad de restitución de un sentido de lo colectivo y de lo histórico, marcado especialmente por el silencio y por la reclusión del solitario o la "Isla"(solitario al que son llevados los detenidos a raíz de un supuesto "castigo"), por una parte, y por la contracara del silencio, el grito, asociado a las situaciones de tortura. Por una parte se piensa a la picana como "uno de los puntos clave del enfrentamiento con los milicos” (1985:24) pero, por otra parte, la reflexión acerca de la tortura tiene que ver en el texto con una metodología de desintegración y no de interrogación: "No hacían ninguna pregunta: sólo daban máquina” (1985:57).

El título alude, (y precedido por una imagen visual que contrasta con al de "los ojos en la nuca" de Sanguinnetti) a la confianza inquebrantable en sus compañeros: con los ojos abiertos, dice Cámpora (1985:98), "decidido a poner siempre[...] las manos en el fuego". El titulo mismo apunta a consolidar este modelo ético que defiende el texto testimonial, además de dejar testimonio de los crímenes del estado. En la cuarta parte, el testimonio de Cámpora aborda de lleno la cuestión de la tortura: "lo que había permanecido en silencio pero develado desde el inicio” (Núñez 214). Las descripciones de la tortura son exhaustivas pero pese al énfasis inevitable en una corporalidad doblegada por el dolor se enfatiza la capacidad de pensar: Esta sección va acompañada por la reflexión acerca de la tortura y por lo que la víctima de la tortura piensa (o teme) y no sólo en el dolor que su cuerpo sufre:

Te van a dar máquina seria, una buena máquina; no las cuatro trompadas del 71, cuando caíste. Tenés miedo, sí, mucho, pero estás dispuesto. La idea de hablar no te pasa por la cabeza: 'la voy a pasar y punto.’ ¿Cómo? Andá a saber: en el momento verás: qué te harán? Submarino, seguro; ¿y picana?: cómo será?, te contesta un vacío perfecto: los cuentos de otros no te sirven. (1985: 226)

Y más adelante:

Desde que la cabeza entró en el agua está ocupada por una sola idea: no me van a sacar a tiempo. Se supone que los milicos no tienen intención de matarlo; pero las piernas al aire, las manos esposadas a la espalda, la cabeza en el agua; sin poder pelear, sin poder avisarles 'miren que ya no puedo más’, preguntándose ”y si calculan mal, si pasan el límite?: la desesperación lo abarca todo: llega finalmente el momento en que lo sacan del agua, pero la desesperación permanece intacta en el cuerpo. (1985: 245)

En el intento de ser reducido a la corporalidad sin pensamiento, sin reflexión, sin palabras, el recuerdo de la tortura misma, de la anticipación, del terror no se representan sólo como dolor sino, en este caso, fundamentalmente como pensamiento.

Al mismo tiempo la descripción de la tortura enfatiza su efecto en el cuerpo, de forma bastante detallada: 
Ana Forcinito. Lavoz visible...

La picana eléctrica produce un dolor agudo, no romo, como de martillo, sino afilado como de aguja, quemante y hondísimo. Se parece al dolor que provoca el taladro del dentista cuando toca el nervio: ese dolor pero extendido a la mitad del cuerpo.

Detrás de los ojos aparecen figuras geométricas multicolores que giran en círculos vertiginosamente o que estallan como fuegos artificiales asombrosos. El cuerpo se contrae en espasmos musculares; no todo el cuerpo, sólo las zonas afectadas y el aire es expulsado con una energía inaudita, pasa por las cuerdas vocales y produce chillidos, exactamente tan agudos como el dolor. (1985: 247)

Descripciones como la anterior elaboran imágenes detalladas del dolor y de una voz que no es tal como voz articulada sino un chillido. Hay un énfasis en la subjetividad capaz de articular una voz narrativa, que traduce en el mismo momento el dolor (lo anticipa, lo explica, intenta hacer sentido de él) o intenta comunicar las imágenes del dolor de la tortura como en el último caso. Lo visual (las figuras geométricas multicolores, los círculos que estallan como fuegos artificiales) ocupa el lugar de la imagen del recuerdo (en lugar del dolor como inenarrable) pero que además reubica a estos cuerpos que sufren la tortura en el escenario de lo visible como sujetos que pueden articular sus derechos a través de un lenguaje comprensible (lo opuesto al grito o al silencio). La reflexión sirve doblemente para poner distancia la narración de la tortura y para explicar el agravio físico desde el diálogo que se entabla con el cuerpo y con el otro, el torturador.: "No quería que me doliera tanto, no quería que me olvidaran en el fondo del tacho" y al mismo tiempo la resistencia: "mi único punto de apoyo era ese silencio resistente" (1985: 249-50). El silencio, espacio inicial de la experiencia carcelaria, no se presenta aquí como parte de la situación de la tortura ni se presenta aquí el cuerpo sino un doble juego entre una subjetividad (consciente del dolor del cuerpo) que elige callar, que quiere callar. EL silencio, que marca la entrada al texto de González Bermejo y que en el primer momento condensa la desaparición del mundo de la militancia, y la entrada a la experiencia del penal, adquiere aquí otro sentido: el de la resistencia. El énfasis en la corporalidad no deja de lado el énfasis en la subjetividad, sino que, por el contrario, se afirma el fracaso de la reducción a la corporalidad justamente a través de la posibilidad de articular la propia voz.

En un texto del 2001 que superpone el relato testimonial y la reflexión sobre la tortura, Carlos Liscano, también se acerca a la afirmación de la subjetividad que tiene lugar en la resistencia del sujeto a través del cuerpo pensamiento que va a devenir en caso de Liscano, escritura: y es la voz la que se subraya, tanto en el grito y el alarido como en la voz articulada de la escritura. El título El furgón de los locos hace alusión al transporte de los últimos presos políticos en marzo de 1985. Es una imagen en movimiento, el furgón de los locos, que los transporta desde el penal a sus casas "desorientado frente al ejercicio de la libertad" (2001: 184) El testimonio comienza con las primeras sensaciones del autor en los primeros días de su detención: Encapuchado, con los zapatos empantanados, desorientado (no sabe qué hora es, aunque sabe que es de noche), acabando de salir de la sala de tortura. Desde el comienzo hay 
referencia a los gritos y a la tortura, y al distanciamiento de su propio dolor, a la suspensión de su pensamiento: sin pensar en nada, ni siquiera en qué siente, se distancia de su cuerpo: "el y yo": "No hay nadie más que nosotros dos” (2001: 7). No se reduce a la corporalidad sino que produce un desdoblamiento (el cuerpo es el que está sucio, dolorido, golpeado. Y el yo, está suspendido: “pasarán muchos años, casi treinta, antes de que pueda decirme qué es lo que siento. No decirme 'qué se siente' sino qué sentimos él y yo 7 " (2001: 7).

Y es tal la centralidad de la voz (la que remite a un grito) que en el exilio, en Estocolmo, la voz lo hace reconocer a una prisionera que él mismo había escuchado: "la loca de los perros", una mujer a quien oyó torturar como detenido. "Como buena presa, ella armaba gran escándalo por lo menos, para que no le preguntaran lo mayor. Si bien no quería que le mataran los perros, tampoco querían que le preguntaran nada. Tenía la esperanza de frenarlos en ese estadio, de modo que se quedaran con la idea de que la posible muerte de los perros la desquiciaba y que por tanto estaba loca. Cada vez que llevaban a Olga a la sala de tortura, oíamos que gritaba: “¡Los perros no, los perros no!” (2001: 49) Más adelante, retorna a esta prisionera y narra la memoria que le quedó de sus gritos, que nunca pudo olvidar, torturada por varios días y cuando el grito de la mujer desaparece y él no sabe si la trasladaron o si murió en la tortura, "la loca de los perros" como la llamaron los presos, quedó en la memoria, hasta poder reconocerla años después en Estocolmo (2001: 118).

El grito es una señal del cuerpo sufriente, un cuerpo en el que Liscano se detiene, con narraciones minuciosas sobre la tortura:

Cuando lo sacan del tacho, la capucha de tela está llena de agua. Entonces una mano cierra la capucha sobre el cuello y el agua demora en salir. La sensación de ahogo continúa unos segundos más. El preso grita y grita. (2001: 68)

Casi como si se demorara en la descripción de cada segundo de una tortura que no se narra en primera persona sino que se refiere al preso, o a los presos en general, la narrativa de Liscano intenta explicar también a una corporalidad en dolor desde un lenguaje ordenador a través del cual se busca tal vez darle una lógica a la reacción del cuerpo frente a los diferentes métodos de tortura y al mismo tiempo, a la conciencia que el preso mantiene: "El preso está aturdido, pero lo cabeza le funciona a gran velocidad” (2001:65). Muchas de las referencias son reflexiones sobre el cuerpo: "El cuerpo está sometido a la asfixia..." Y así distancia ese yo de muchos años después ("muchos años después enfermo y sin poder mover los brazos, llegaré a la conclusión de que el dolor físico es una puerta de acceso al

\footnotetext{
${ }^{7}$ A partir de ahí Liscano salta a su infancia y a la narración que concluye con el nacimiento de su hermana en 1956 para dar luego otro salto al 27 de mayo de 1972, la fecha de su detención. El testimonio detecta, dos comienzos: el de la vida y el de la detención: "Los presos tienen pasión, y desesperación, por aprovechar el tiempo. Hay que hacer algo positivo, algo por la vida, no dejarse aplastar por las rejas.” (18) La narrativa de la primera parte va hasta 1985 año en el cual lo liberan junto con otros presos políticos.
} 
Ana Forcinito. Lavoz visible...

autoconocimiento." (2001:99). El dolor es el protagonista de estas reflexiones, pero son reflexiones que surgen de una subjetividad muy posterior, suspendida, durante el momento del dolor. Y la recuperación del puente histórico entre la subjetividad del presente (como sujeto de la escritura y la reflexión) y la del pasado resulta no sólo (no tanto) de la narración como de la estrategia narrativa, esa separación del cuerpo y del sujeto, por ejemplo, y ese intento de reconstruir un puente entre ambos que implica el paso de muchos años y el recuerdo no tanto del pensamiento (suspendido) sino de lo que no se pensó.

Pero no se me ocurre pensar que la tortura y la cárcel serán para siempre, que algún día acabaré escribiendo sobre esto, sobre esta miseria. Que mi vida será inimaginable para mí sin esto que estoy viviendo, sin los trece años que viviré. Y que acabaré diciéndome, y no una vez sino muchas, con una convicción primitiva que va mucho más allá de la literatura, del más o menos hábil oficio de enhebrar palabras, que si hubiera sido posible otra vida, para mí yo no la elegiría (2001: 108).

Al final, Liscano reflexiona (desde un presente en el pasado que piensa en tiempo futuro) sobre lo que recién muchos años después podrá narrar. Esta reflexión final (sobre el cuerpo y sobre ese sujeto suspendido que se define a través de la escritura) marca esa nueva subjetividad cuya marca es el pasaje de la voz no articulada al lenguaje (volviendo a Ranciere aquí esa diferencia entre los cuerpos parlantes y los cuerpos sin palabras): “Aquí aprenderé mucho de otros presos[...]Pasaré fríos[...] Comenzaré a escribir. Decidiré que seré escritor.” (2001:181) Y luego de hablar de los años que siguen a su libertad, a las nuevas obsesiones (centradas alrededor de escribir), dice:

Pasarán veintisiete años antes de que encuentre una voz que pueda hablar de los viejos tiempos. Un día la voz entenderá que la relación entre el individuo aislado y las palabras tiene suficiente jerarquía e interés literario como para ser contada y escribiré “el lenguaje de la soledad” y creeré que eso es todo lo que soy capaz de decir.

Pero otro día, un año después, de golpe, la voz se abrirá camino, se me impondrá, querrá decir, contar, con o sin jerarquía, con o sin calidad literaria. Y la voz será indetenible, me dirá qué escribir, rescatará hechos, sensaciones, sentimientos que no recordaba. (2001: 183-84)

Existe una voz, la del grito que es la que escuchamos y que va dando lugar a esa otra voz que estuvo muda, separada del cuerpo, la voz articulada que es capaz de narrar, de hacerse visible. Es la que al final nos dice que esa es su vida y que si hubiera habido otro modo de vivir, no lo hubiese elegido, si bien

La vida pasó y nada fue como decíamos

Fue la cárcel, fue la tortura fueron los

Miles de muertos (2001: 184) 
Ana Forcinito. La voz visible...

\section{Temporalidad y subjetividad: Memorias del calabozo, Vivir en Libertad y El almanaque}

El eje de la resistencia y de la construcción del sujeto ético político proyectado tanto hacia la recuperación del sentido histórico (quien ha de narrar el pasado) como hacia el futuro (quien ha de articular el sentido de lo político en el futuro) puede verse en lo que tal vez es el testimonio clave de este primer periodo de justicia transicional, las Memorias del calabozo (1987) de los dirigentes tupamaros Mauricio Rosencof y Eleuterio Fernández Huidobro. Ambos fueron rehenes de la dictadura, según ellos mismos explican porque "cualquier cosa que hiciera el MLN sería contestada con la muerte y el castigo corporal en esos nueve militantes” (Volumen I, 118). Como la mayoría de los aportes testimoniales, el diálogo entre Fernández Huidobro y Rosencof se ancla en la descripción de las condiciones de vida, la reducción a la corporalidad, la tortura, la humillación, los traslados de calabozos y el traslado al Penal Libertad y las estrategias de resistencia que utilizan para sobrevivir.

Dos imágenes, ambas conectadas a la visión, a su pérdida y a su recuperación, sirven para capturar dos momentos diferentes de la experiencia carcelaria: Una de ellas, es la de la capucha, asociada a la experiencia del rehén y a su pérdida del mundo que lo rodea, incluso el sentido de la temporalidad. Ese primer momento, marcado auditivamente por el silencio se condensa en la presencia de la capucha. Dice Fernández Huidobro: "El mundo del silencio, el mundo de la desolación. Lo único: la capucha.” (2000: 18). Rosencof toma esta imagen y la desplaza en el espacio: "Capucha se convirtió en polifuncional. La cuidábamos, la dábamos vuelta, la sacudíamos, la oreábamos.”[...] Finalmente te echabas sobre el piso. Y la capucha era el colchón.” (2000: 18). La capucha y el silencio enfatizan (pese al movimiento que aporta su multifuncionalidad) dos ausencias: la del sonido y la visión en el aislamiento (frente por ejemplo al escenario de la tortura marcado por voces y gritos). No se trata de no poder ver: se mencionan las huellas que se fueron dejando en los calabozos, ellos mismos se sacan la capucha al llegar a la celda y hay referencias a lo visto dentro de la celda, se trata, además de una metáfora de la vida del rehén, acompañado del símbolo recordatorio de la violencia ejercida contra él, de su degradación.

La otra imagen que quiero destacar (y que implica un acercamiento hiperbólico a la visión, de las numerosas que habitan el texto, es la ventanita-ventanal (ventanita para Fernández Huidobro, ventanal para Rosencof) tapado con papel azul: "Aquel maravilloso ventanal por el que sonábamos con volver a Melo en cada traslado que en lo sucesivo se iba a producir (2000: 37). Se trataba de una ventana que no cerraba bien y por la cual era posible ver "el cielo y esa cosa maravillosa: las copas de los naranjos que bordeaban la plaza de armas" (2000: 38) y por la cual una vez entra un pájaro a su celda (que interpretan como vaticinio de la libertad (aunque Rosencof le dice a Fernández Huidobro: "Vos auguraste la libertad, pero pifiaste en los plazos." 2000: 38).

\footnotetext{
${ }^{8}$ De los rehenes (Adolfo Wasem, Raul Sendic, Jorge Manera, José Mujica, Julio Marenales, Jorge Zabalza, Henry Engler, Eleuterio Fernández Huidobro y Rosencof) todos sobreviven excepto Adolfo Wasem.
} 
Ana Forcinito. La voz visible...

El diálogo, aunque marcadamente testimonial, (y como puede verse en las citas anteriores no desprovisto de sentido del humor) apela a ciertas condensaciones que sirven de metáfora para evocar e interpretar la experiencia. Al mismo tiempo son la visión y el oído (la luz, la oscuridad, la capucha, el silencio, los ruidos, los gritos) los que sirven para describir los lugares de confinamiento (eran trasladados con frecuencia y de ahí la importancia de todos los detalles)

Hay un intento de dar cuenta de los eventos ordenadamente, o de poder detectar o reconstruir un orden temporal que remite a lo histórico. Este ejercicio de memoria de Memorias del calabozo parece ligado a la tarea de memorialización y de construcción de archivos (de ahí el carácter casi de crónica, la insistencia en las fechas, en los años en los días, en todo aquello que pueda restituir justamente ese sentido de temporalidad perdido que se recupera en la narración. El tiempo transcurría y eso es lo que intentan reorganizar Fernández Huidobro y Rosencof. Hubo 45 traslados e intentan ubicarlos en el tiempo a través de todas las conexiones que pueden establecer con marcas temporales. Sin embargo, el sentido del tiempo (y esto se menciona varias veces) se experimenta como perdido, como continuo, fuera del almanaque que fija las fechas.

En un testimonio publicado mucho más recientemente, Vivir en libertad (2003), de Jorge Tiscornia podemos ver esta organización de lo temporal, como una crónica de la experiencia que contrasta con más recientes acercamientos a una temporalidad confusa que genera nuevas imágenes para la memoria. Tiscornia, en cambio, (también puede verse en El almanaque, del mismo Tiscornia, luego dirigida por Juan Pedro Charlo) registra el almanaque de los 4,646 días en el penal de Libertad. Un intento de "fijar" la memoria de la prisión prolongada. En Vivir en libertad Tiscornia se refiere a un almanaque casero que le permitía ordenar los días y anotar acontecimientos: "Trataba de registrar los sucesos graves. La muerte de un compañero, la enfermedad de otro, los traslados al hospital,...las salidas sin retorno." (2012: 17) El almanaque (2012) compilado por Charlo y el mismo Tiscornia ofrece además del almanaque de más de doce años (día por día un almanaque con marcas y anotaciones, separadas del libro, agrupadas por años) una compilación de textos en torno al significado del almanaque, como "soporte físico" dice Elbio Ferrario, director del museo de la memoria (también ex preso político) y lo compara con las "piedritas que brillando como plata, le indicaron el camino" a Hansel y Gretel como ese instrumento que permite descifrar el pasado. Charlo, por su parte se re refiere a la historia de los suecos donde Tiscornia esconde los almanaques (2012: 15), y al proceso mismo de filmación del documental. Se trata de registrar las fechas de lo que sucedía desde las visitas a las radiografías: "Registros.Hilvanados con empecinamiento." "parches del olvido" "Lupa antigua" Trazos hechos en el viaje" son algunas de las asociaciones que propone el mismo Tiscornia (2012: 86). El almanaque enfatiza el gesto ordenador de una realidad que escapaba a lógica y que se resistía al recuerdo claro de las posterioridades y las anterioridades a cada evento. Así los eventos fueron registrados creando 
Ana Forcinito. La voz visible...

un doble registro: el del tiempo marcado día a día, el del registro minucioso, que se entrelaza a la confusión de días interminables, a la pérdida de la noción del tiempo. Casi como el archivo de una bruma, donde la creatividad consiste justamente en señalar la precisión. ${ }^{9}$ ¿Qué más artístico, después de todo, que el registro testimonial donde quedan anotados tantos de los eventos de la cotidianeidad de más de doce años?

La política, para Rancière, "se refiere a lo que vemos y podemos decir, a quien tiene la competencia para ver y la cualidad para decir" ("Del reparto" 1996: 20). Rancière se refiere a una conflictividad entre los que tienen voz articulada (lógica) y voz como sonido (los que hablan desde la distorsión). La política está regida por el logos, la palabra. Y son los cuerpos que tienen nombre los que ocupan el lugar de lo visible, mientras que los que no lo tienen ocupan el lugar de lo invisible. Es lo que Rancière llama el reparto de lo sensible y que tiene que ver con el reparto de los lugares, de los tiempos, de las partes. (2006: 20). Ahí entra en juego la ley que regula los modos perceptivos. La política existe, para Rancière, porque los que no tienen parte (y no tienen derecho a ser contados) se hacen contar. "La actividad política es la que desplaza a un cuerpo del lugar que le estaba asignado o cambia el destino de un lugar; hace ver lo que no tenía razón para ser visto, hace escuchar un discurso allí donde sólo el ruido tenía lugar, hace escuchar como discurso lo que no era escuchado más que como ruido” (1996: 45).

Estos testimonios recomponen la voz articulada y hacen visible no solo los sujetos de esa voz (cuerpos parlantes, según los define Rancière, o cuerpos- pensamiento para Badiou) sino la propia mirada sobre sí y el mundo: es decir cuerpos parlantes que son además sujetos de la mirada. Estos testimonios, claro está, dan cuenta de violaciones a los derechos humanos y al mismo tiempo ejercitan un gesto político, el de reconstruir la trama política de la transición que había señalado la derrota política de los militantes de los setenta a través del gesto inaugural de la liberación de rehenes y presos políticos como trofeos de guerra. Así el testimonio reconstruye la figura política de los ex presos para dejar a los otros (los represores) únicamente la victoria militar. Hay una articulación de lo político, que se hace desde el reclamo de haber sido víctimas, en la medida que nos invita a ver un cuerpo sufriente, pero con una voz articulada (es decir, con una lógica y un pensamiento). La centralidad de la víctima (en el sentido de Badiou con la cual comencé este ensayo) que propone el testimonio reside no solo en el dispositivo de la acusación sino además es clave en la reconfiguración del orden de lo visible y de lo audible y en la proyección de las figuras políticas (las que son clave en el Uruguay del presente) y que se forjan, puede proponerse, desde los gestos testimoniales que se dan inicio en el discurso de Conventuales.

No pretendo negar o cuestionar la relación directa y expresa que los testimonios han tenido y siguen teniendo en los mapas de las posdictaduras con las luchas por los derechos humanos. Lo qué

\footnotetext{
9 Ana Tiscornia desde su mirada artística, propone ver los almanaques como dibujos, enfatizando el gesto creador y la demarcación del borde o la línea característica del acto de dibujar.
} 
intento subrayar es que esas luchas implican un pasaje por lo político, que está sustentado en la inauguración de una nueva subjetividad con voz visible que puede condensarse en la imagen de "poder mirar a los hijos a los ojos", es decir, una subjetividad marcada por el sentido de la ética ${ }^{10}$

Vuelvo a algunas de las preguntas iniciales: ¿Quién es la víctima? ¿Quién es considerado víctima? Pero además ¿Cómo se exponen las violaciones a los derechos humanos en la transmutación de un cuerpo espectáculo (que conlleva el goce del espectador) o un cuerpo sufriente (que puede conllevar la piedad) a un cuerpo asociado al pensamiento (según la propuesta de Badiou) y a la ética, como he discutido en estos testimonios y a un fuerte sentido histórico (marcado por el énfasis en la temporalidad) que permite desmontar, en el campo de la cultura, las bases de un proceso de pacificación escenificado en el gesto de la liberación de los rehenes como fin del enfrentamiento armado. Frente a la caducidad de la pretensión punitiva del estado, la literatura fue el espacio en el cual se va forjando el reclamo de las víctimas constituidas además como subjetividades políticas (del pasado y del futuro). El testimonio cumplió y sigue cumpliendo un rol central en el diseño de los espacios para habilitar de entrada de cuerpos visibles (puede pensarse en la bastante reciente entrada de los cuerpos de las mujeres y sus reclamos de violencia sexual) y de voces articuladas que no solo denuncian los crímenes, y construyen los símbolos culturales que pueden llegar a sustentar un proyecto de justicia, sino que además intentan consolidar la proyección política hacia un futuro que propone el trabajo de la memoria como uno de sus aspectos más salientes en la medida en que pone en escena las confictividades y los disensos que el discurso de la pacificación y del consenso de caducidad parecen invisibilizar.

\footnotetext{
${ }^{10}$ Este pasaje de ex rehén y ex preso a sujeto político de la democracia implica también una aceptación del proceso de justicia transicional, un proceso cuyo gesto fundacional en el terreno legal es la Ley de Caducidad (que van seguidos a lo largo de los años por los dos plebiscitos que la afirman (1989-2009) y por la declaración inconstitucional de la nulidad de los artículos 2 y 3 de la ley (en febrero de 2013).
} 
Ana Forcinito. Lavoz visible...

\section{Bibliografía}

Agamben, Giorgio (1998). Homo Sacer: Sovereign Power and Bare Life. Stanford: Stanford University Press.

Badiou, Alain (2007). "La idea de justicia”. Justicia, filosofía y literatura. Silvana Carozzi, (eda). Buenos Aires: Homo Sapiens.

Beverley, John (1993). Against Literture. Minneapolis: University of Minnesota Press.

Beverley, John y Hugo Achugar (2002). La voz del Otro. Guatemala: Abrapalabra .

Butazzoni, Fernando (1986). El tigre y la nieve. Montevideo: Ediciones de la Banda Oriental.

Butler, Judith (2009). Frames of War: When is Life Grievable? London: Verso.

Caetano, Gerardo. "The Citizen's Testament and the Necessary Risks of Truth: Accounts Pending in Contemporary Uruguay." (Human Rights and Latin American Cultural Studies. Ana Forcinito y Fernando Ordoñez, eds). Hispanic Issues on Line 4(2009) 85-136.

Delgado, Maria (2000). "Truth and Justice in Uruguay." NACLA Report on the Americas 34: 37-53.

El Referendum uruguayo del 16 de abril de 1989. Instituto interamericano de Derechos Humanos, Costa Rica, 1989.

Forcinito, Ana (2012). Los umbrales del testimonio: entre las narraciones de los sobrevivientes y las marcas de la posdictadura. Madrid: Ibeoramericana.

Fried, Gabriela y Francesca Lessa (2011). Luchas Contra La Impunidad: Uruguay, 1985-2011. Montevideo: Trilce.

González Bermejo, Ernesto (1985). Las manos en el fuego. Montevideo: Ediciones de la Banda Oriental.

Halbwachs, Maurice (1980). On Collective Memory. New York: Harper \& Row.

Huyssen, Andreas (2003). Present Pasts: Urban Palimpsests and the Politics of Memory. Stanford: Stanford University Press.

Liscano, Carlos (2001). Elfurgón de los locos. Montevideo: Planeta.

Moraña, Mabel (1988). Memorias De La Generación Fantasma: Crítica Literaria 1973 - 1988. Montevideo: Ed. Monte Sexto. 
Ana Forcinito. Lavoz visible...

Phillipps-Treby y Jorge Tiscornia (2003). Vivir en libertad. Montevideo: Ediciones de la Banda Oriental.

Rancière, Jacques (1996). El desacuerdo política y filosofía. Buenos Aires: Ediciones Nueva Visión.

Rancière, Jacques (2009). El reparto de lo sensible: estética y política. Santiago de Chile: LOM.

Roniger, Luis y Mario Sznajder (1999). Legacy of Human-Rights Violations in the Southern Cone: Argentina, Chile and Uruguay. New York: Oxford University Press.

Rosencoff, Mauricio y Eleuterio Fernandez, Huidobro (2000). Memorias del calabozo. Tres volúmenes. Montevideo: Ediciones de la Banda Oriental.

Roht Arriaza, Naomi (2014). From Amnesty to Accountability: Transitional Justice in South America. Nueva York. World Politics Review.

Ruiz, Marisa y Rafael Sansaviero (2012). Las rehenas: historia oculta de once presas de la dictadura. Montevideo: Fin de Siglo.

Servicio Paz y Justicia, Uruguay (1992). Uruguay, Nunca Más: Human Rights Violations 1972-1985. Philadelphia, Temple University Press.

Tiscornia, Jorge y Jose Pedro Charlo (2012). El almanaque. Montevideo: Yauguru.

Viñar, Marcelo y Daniel Gil. (1997). "La dictadura: una intrusión en la intimidad.” Historia de la vida privada en el Urugua. Tomo 3: Individuos y soledades 1920-1990. José Pedro Barrán, Gerardo Caetano y Teresa Porzecanski, (eds). . Montevideo: Taurus.

Weinstein, Martín (1993). "The decline and fall of Democracy in Uruguay: Lessons for the Future." Repression, Exile and Democracy: Uruguayan Culture. Saul Sosnowski (ed). Nurham: Duke University Press.

Weiss Fagen, Patricia (1992). "Repression and State Security." Fear at the Edge: State Terror and Resistance in Latin America. Juan Corradi, Patricia Weiss Fagen y Manuel Antonio Carretón, eds. Berkeley: University of California Press. 